\title{
STRENGTHENING OF REINFORCED CONCRETE BEAMS WITH CARBON FIBER REINFORCED POLYMERS
}

\author{
Ayman Gr. Abdel-Rahman and Faiz A. Mirza \\ Civil Engineering Department, College of Engineering and Islamic Architecture \\ Umm Al-Qura University, P.O. Box 6298, Makkah, Saudi Arabia
}

\begin{abstract}
Strengthening of structures is a complex task. Different systems can be used in order to utilize the fiber reinforced polymer in the most efficient way. Two techniques for surface reinforcement in reinforced concrete beams are addressed in this paper, namely, externally bonded laminates (EBL) and near surface mounted strips (NSM). The experimental work involves seven full-scale reinforced concrete beams strengthened with carbon fiber reinforced polymers (CFRP) and tested up to failure to illustrate two methods of field application and construction techniques of strengthening. The performance and effectiveness of these techniques are demonstrated by comparing the test results of both strengthened and un-strengthened beams. Test results indicate that both techniques are effective in increasing the flexural capacity of R.C. beams. Also it was observed that the beams strengthened with NSM reinforcements show different failure modes than the externally bonded FRP. Applications of the two methods of strengthening R.C beams are suitable for all cases, but prior to the installation of surface bonded CFRP reinforcement, attention should be directed toward investigating the surface concrete on which the composites are to be
\end{abstract} bonded.

تعثبر ثثوية المنشآت باستخدام ألواح البوليمرات المسلحة بألياف الكربون من أكثر الطرق فاعلية في تقوية

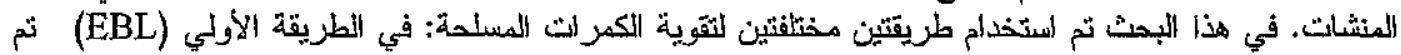

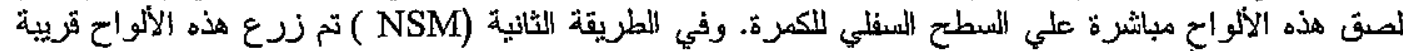

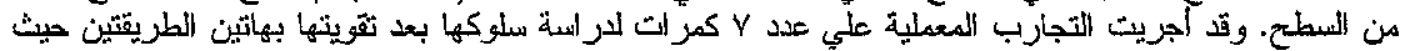

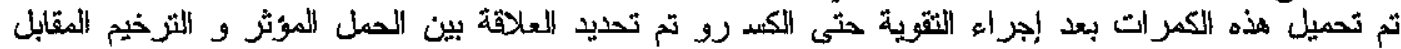

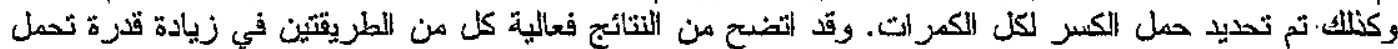

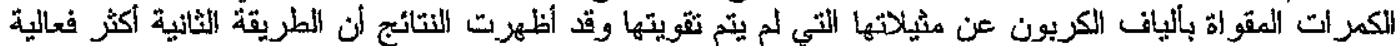

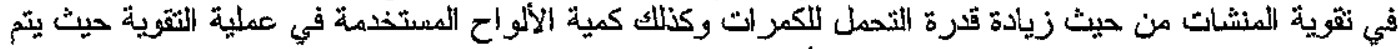

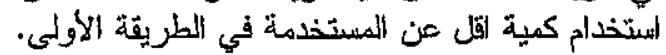

Keywords: Flexural Strengthening; Carbon Fiber Reinforced Polymers; Externally Bonded Laminates; Near Surface Mounted Strips; Modes of Failure.

\section{INTRODUCTION}

Fiber-reinforced polymer "FRP" reinforcement became very attractive in the field of reinforced concrete structures both for new constructions strengthening or upgrading of existing structures. The success of the composite reinforcement is mainly linked to their high mechanical performances, low weight, satisfactory durability in an aggressive environment. Several applications for FRP reinforcements have been made all over the world and an increasing market with a high variety of reinforcement is registered at present, [1].

Science 1982, externally bonded (EB) FRP sheet / strip has been successfully applied to strengthen concrete structures, [2]. Although externally bonded FRP reinforcement performed externally well in practice, premature debonding failure was observed and identified by many researches $[3,4,5]$. Several details were proposed to avoid this type of failure, which is unacceptable from the point of view of structural safety, [6,7].

Near surface mounting (NSM) FRP technique has many advantages compared with the externally bonding (EB) technique; larger bond surface induces better anchorage capacity, provides higher resistance against peeling-off, a higher percentage of the tensile strength can be mobilized, and no preparation work is needed other than grooving, therefore reduced installation time will be required, [8]. FRP reinforcement due the special mounting setup is protected against mechanical by the surrounding concrete influence, therefore, this technique is attractive for strengthening in the negative moment region. The strengthening has an improved protection against freeze/thaw cycles, elevated temperature, fire, ultraviolet rays and vandalism, $[9,10,11]$.

A series of R.C beams strengthened with near surface mounted (NSM) CFRP strips were tested up to 
failure. Test results demonstrated the effectiveness of this technique compared with the externally bonded technique. The results showed a substantial increase in cracking and failure loads for strengthened specimens. The experiments showed also improvement in ductility, preferable composite action, and an ultimate load development more independent from concrete tensile strength, $[12,13,14]$.

Now there is a great potential in FRP strengthening, however, it is important to have sufficient knowledge on the behavior and applicability of different FRP materials and techniques. This paper presents an experimental investigation to evaluate the performance and effectiveness of both externally bonded laminates and near surface mounted strips techniques by comparing the test results of strengthened and the unstrengthened beams.

\section{EXPERIMENTAL WORK}

This experimental work is carried out in order to evaluate the effect of Externally Bonded(EB), as well as Near Surface Mounted(NSM), Carbon Fiber Reinforced Polymers (CFRP) on the flexural behavior of reinforced concrete beams.

A total of seven full scale simply supported rectangular beams are tested. All the seven beams had clear span length $2.80 \mathrm{~m}$ (beams were $3 \mathrm{~m}$ long) and cross-section dimensions of $20 \times 50 \mathrm{~cm}$. These beams had an internal reinforcement provided by top reinforcement consisted of two $10 \mathrm{~mm}$ in diameter steel bars, and a bottom reinforcement consisted of three $16 \mathrm{~mm}$ in diameter steel rebars running along the full length of the beam. Shear reinforcement consisted of double-legged steel stirrups $(8 \mathrm{~mm}$ in diameter), uniformly spaced at $125 \mathrm{~mm}$, as shown in Fig. 1.

One beam (beam B1) was tested as a control specimen, while three other beams (B2, B3, B4) were strengthened with one, two, and three adjacent strips of externally bonded CFRP reinforcement respectively. The other three beams (B5, B6, B7) were strengthened using one, two, and three CFRP strips of near surface mounted CFRP inserted into grooves cut at the bottom surface of the beams.

\subsection{Materials}

The characteristics of the materials used in the present work are described in the following:

1. Concrete of compressive strength $35 \mathrm{MPa}$ was used in the present work. The beams were reinforced by high grade steel with yield strength of $400 \mathrm{MPa}$ and an ultimate strength of $600 \mathrm{MPa}$.

2. Composite material CFRP has been used in this experimental work, named "CarboDur" which is a pultruded carbon fiber reinforced polymers laminates designed for strengthening of concrete structures. Sika CarboDur was bonded to the RC beams as an external reinforcement using an epoxy resin conforms to the current ASTM C-881 and AASHTO M-235 specifications. The properties of CFRP laminates are reported in Table 1.

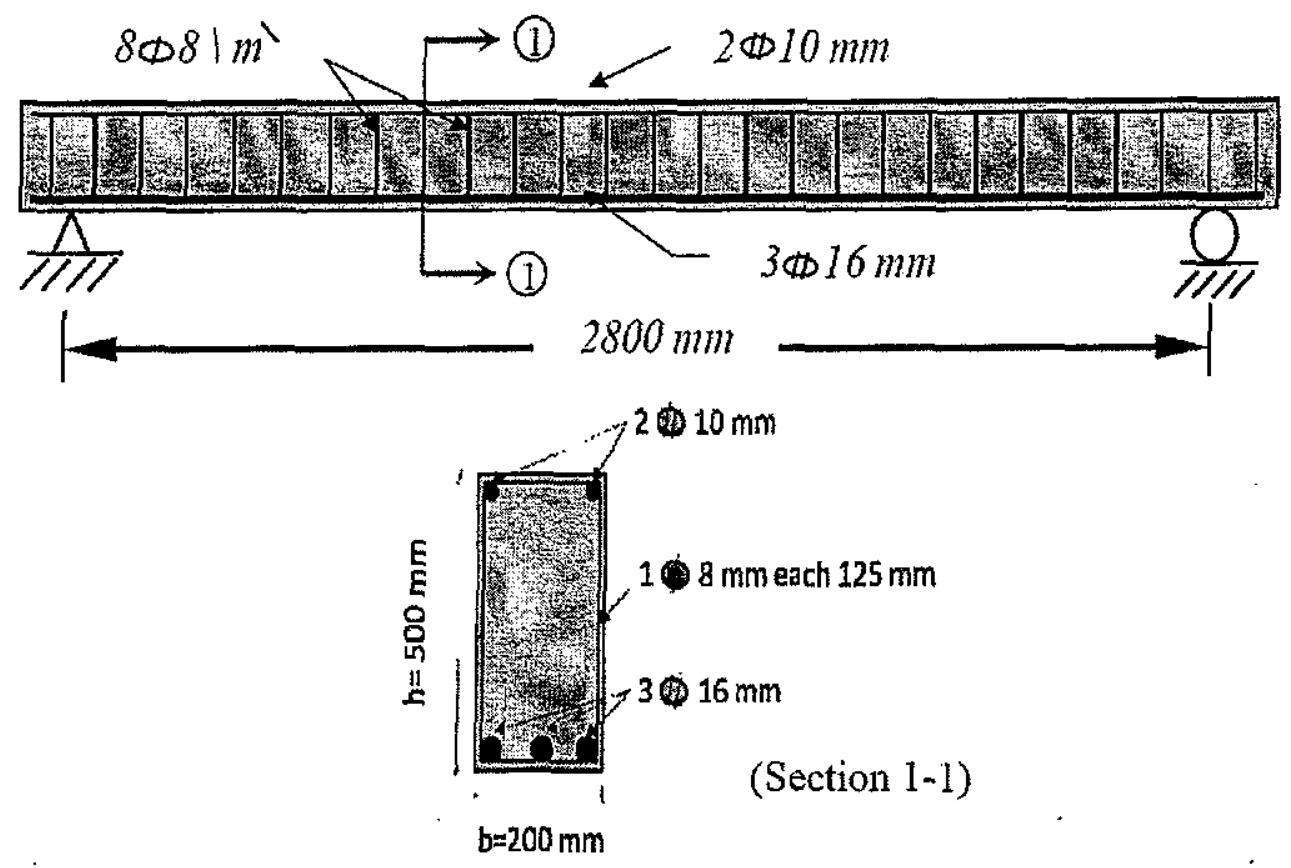

Fig. 1: Beam details 
Table 1: Properties of CFRP laminates.

\begin{tabular}{|c|c|}
\hline & \\
\hline 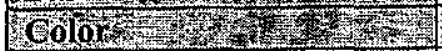 & 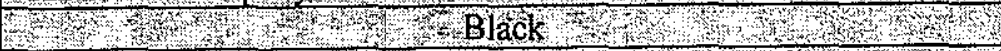 \\
\hline Tensilestrength & 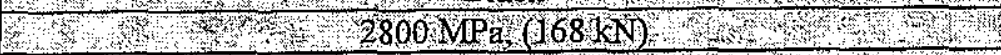 \\
\hline Modulus of $\mathrm{EHas}$ acity & W $160000 \mathrm{Mpd}$ \\
\hline 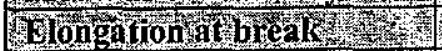 & W. Wh Wh \\
\hline ran & What \\
\hline Ther ness & Wh \\
\hline 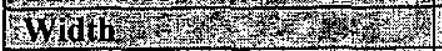 & W \\
\hline$x^{4}$ & (3) \\
\hline 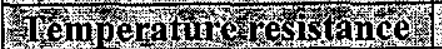 & W \\
\hline Miberyoli & ren \\
\hline 3 & 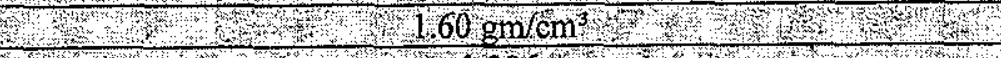 \\
\hline & \\
\hline
\end{tabular}

\subsection{SPECIMENS PREPARATION AND STRENGTHENING}

All tested beams were cast in wooden forms of dimensions $20 \times 50 \times 300 \mathrm{~cm}$ using ready-mix concrete of $35 \mathrm{MPa}$. After one day, the wooden forms were de-molded and all beams were cured by tap water for seven days and tested after about one month.

\subsection{Strengthening with externally bonded CFRP \\ 1. Surface preparation:}

The concrete surface was grinded to a concrete surface profile (CSP) 3 , as defined by the International Concrete Research Institute (ICRn). Then the surface was cleaned carefully. After that, large holes and irregularities on the surface were filled with putty.

\section{Application of the resin \& CFRP:}

Epoxy paste was prepared by mixing its components in certain proportions. During its pot life, the paste was applied to the surface of beams with a spatula to a minimum thickness $1.5 \mathrm{~mm}$. At the same time, the epoxy paste was applied on the CFRP laminates by the same thickness $(1.5 \mathrm{~mm})$. The CFRP laminates were then placed on the concrete surface within the pot life of the epoxy paste (each of $50 \mathrm{~mm}$ width as shown in Fig. 2). Then the laminates were pressed into the epoxy resin until the adhesive was forced out on both sides using a hard rubber roller, The excess adhesive was then removed. Wrapping anchorage using FRP sheets was applied only for a length of 20 $\mathrm{cm}$ apart of the support of beams strengthened with externally bonded CFRP (B2, B3, and B4) to eliminate the possibility of failure as a result of splitting of the externally bonded CFRP. The above mentioned procedure for the strengthening of the beams with CFRP laminated is shown in Fig. 2.

\subsection{Strengthening with near surface mounted CFRP}

The strips, as provided by the manufacturer, have a nominal width of $50 \mathrm{~mm}$ and a total thickness of $1.2 \mathrm{~mm}$. In order to insert the strip within a typical concrete cover used for concrete members, the strips were cut into two halves each $25 \mathrm{~mm}$ wide. Using a concrete saw, approximately $5 \mathrm{~mm}$ wide and $25 \mathrm{~mm}$ deep grooves were cut into the bottom surface of the beams. The grooves were injected with epoxy adhesive to provide the necessary bond with the surrounding concrete. The strips were carefully placed into the grooves to ensure that they were completely covered with epoxy. Strengthening beams by the NSM strips is illustrated in Fig. 3 .

\subsection{Test Set-up and Instrumentation}

The beams were tested under two point loads applied at one meter span. The vertical deflections at midspan and the strains in concrete and steel were measured using strain gauges.

The deflectometer used to measure the vertical deflection at mid-span is located at point (1), the strain gauge used to measure tensile strain in steel is positioned at point (2), while compressive strains in concrete was measured by two strain gauges located at points $(3,4)$, finally the tensile strains in the composite materials are measured using strain gauges installed at mid-span at point (5). The distribution and location of the strain gauges used are shown in Fig. 4.

The beams were tested under open steel frame with a maximum capacity of $1000 \mathrm{KN}$. The load was applied in an increment of $20 \mathrm{KN}$, and the corresponding deflections and strains were reported. All beams were painted by plastic white paint to observe the crack generation and propagation (map cracking). 

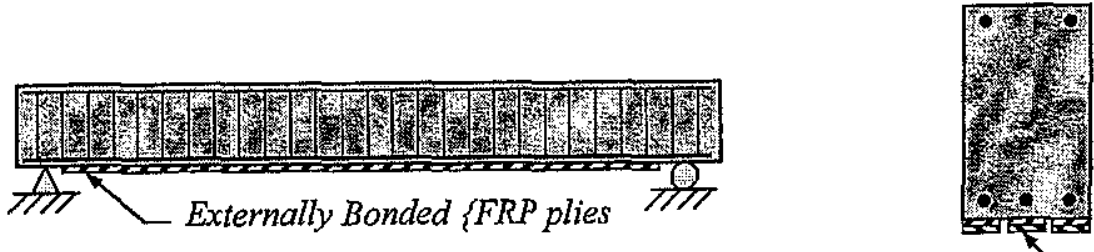

Externally Bonded CFRP

Fig. 2: Strengthening with externally bonded CFRP
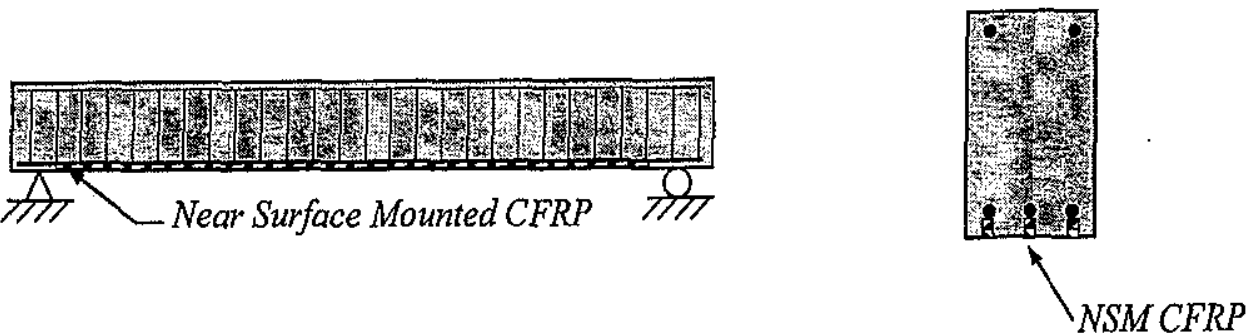

Fig. 3: Strengthening with NSM CFRP.

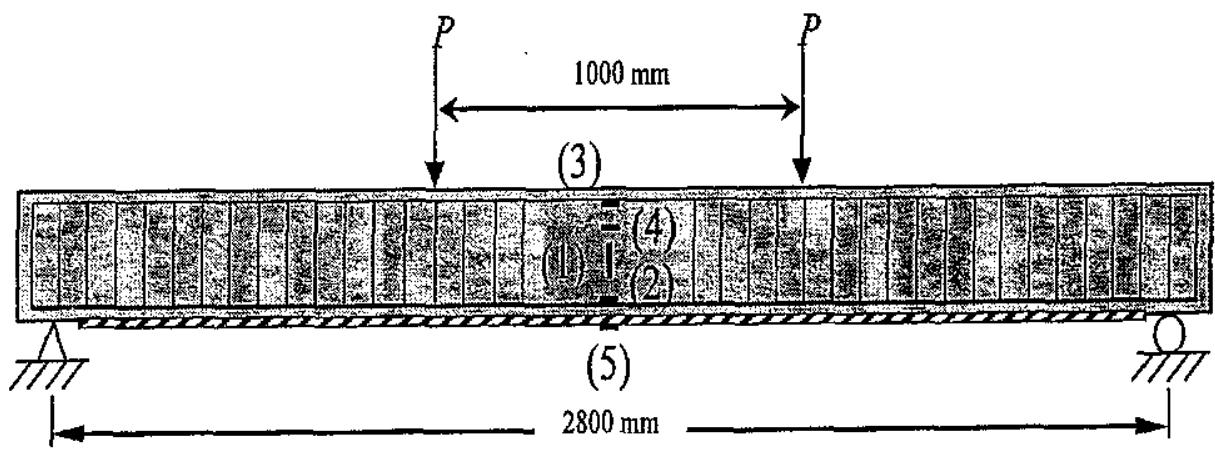

Fig. 4: Test set-up and location of the strain gauges

\section{RESULTS AND DISCUSSIONS}

The present work investigated the effect of using two strengthening techniques; the first one was externally bonded CFRP, while the second technique was the near surface mounted CFRP reinforcements, on the flexural behavior of reinforced concrete beams.

A total of seven simply supported rectangular beams were tested up to failure. The flexural behavior was investigated in terms of flexure capacity, loaddeflection relationships, strains induced in concrete and steel reinforcements, and modes of failure of the tested beams. The performance and effectiveness of the two strengthening techniques were demonstrated by comparing the test results of the strengthened and the un-strengthened beams. Test results are summarized in Table 3. Curves were plotted to explain the behavior of tested beams under static load up to failure.

In general, the control beam developed flexural tensile cracks in the constant moment regions at load of $100 \mathrm{kN}$. At loads near $300 \mathrm{kN}$, the tensile reinforcing steel yielded. Finally, the beam failed in compression due to crushing of extreme compression concrete fibers at load of $340 \mathrm{KN}$ (compression failure).

All beams strengthened with Externally Bonded CFRP as well as NSM CFRP showed significant increases in flexural stiffness and ultimate capacity as compared with the control beam.

\subsection{Flexural behavior of beams strengthened by externally bonded (EB) CFRP}

Beams strengthened with one, two, and three externally bonded CFRP (B2, B3, and B4) had an increase in the ultimate load by $31 \%, 60 \%$, and $89 \%$ respectively over the control beam (B1) as shown in Table 2. The measured mid-span deflection of the $\mathrm{EB}$ strengthened beams were $26.5 \mathrm{~mm}, 24 \mathrm{~mm}$, and $22 \mathrm{~mm}$ respectively, while the mid-span deflection value for the control beam was $28 \mathrm{~mm}$. The relationship between mid-span deflections and the applied load up to failure for beams strengthened with EB CFRP laminates is illustrated in Fig. 5. From this figure, similar behavior for all beams could be observed except that as the number of strips increased the load at which the first crack occurred is increased too. 
Table 2: Experimental results for tested beams

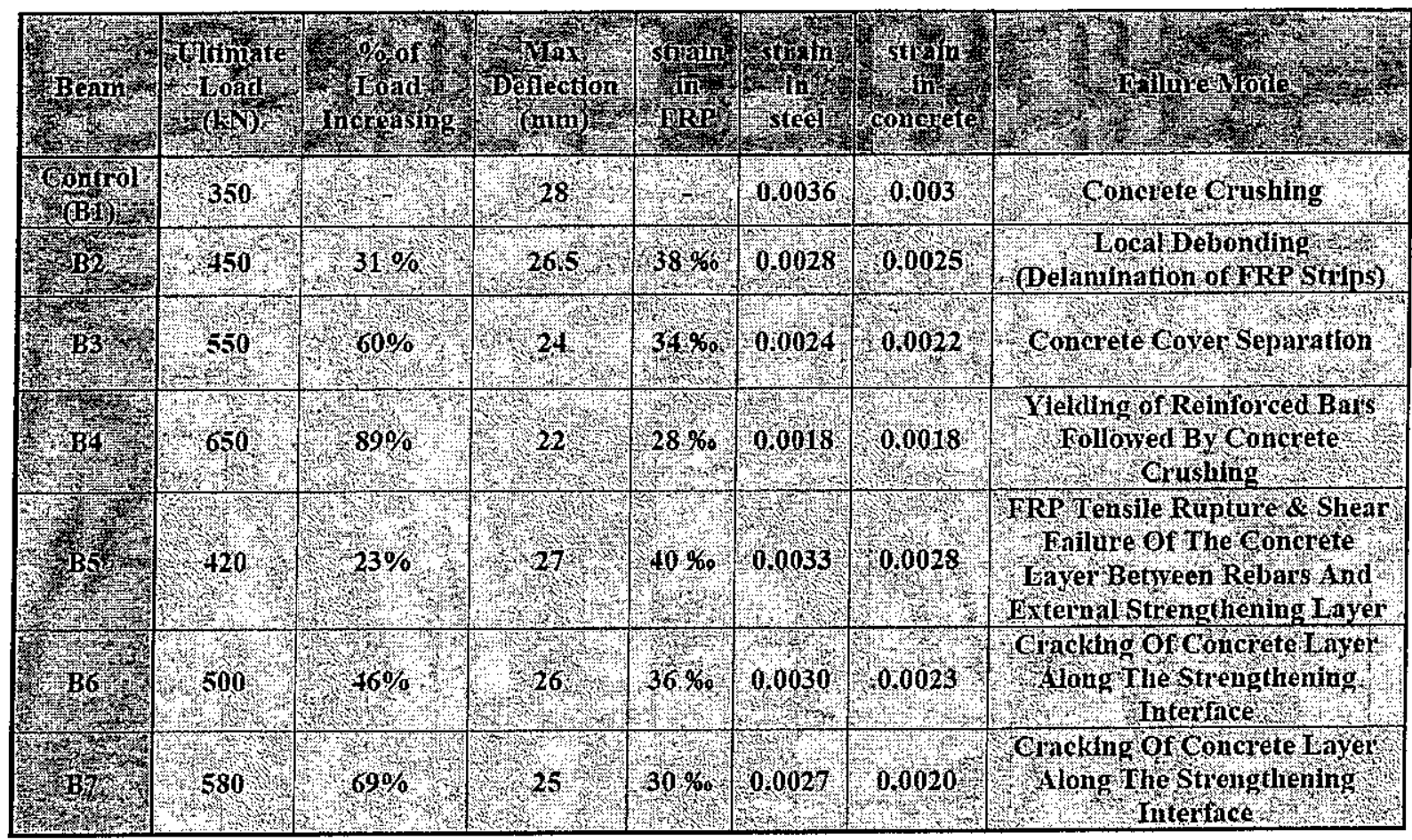

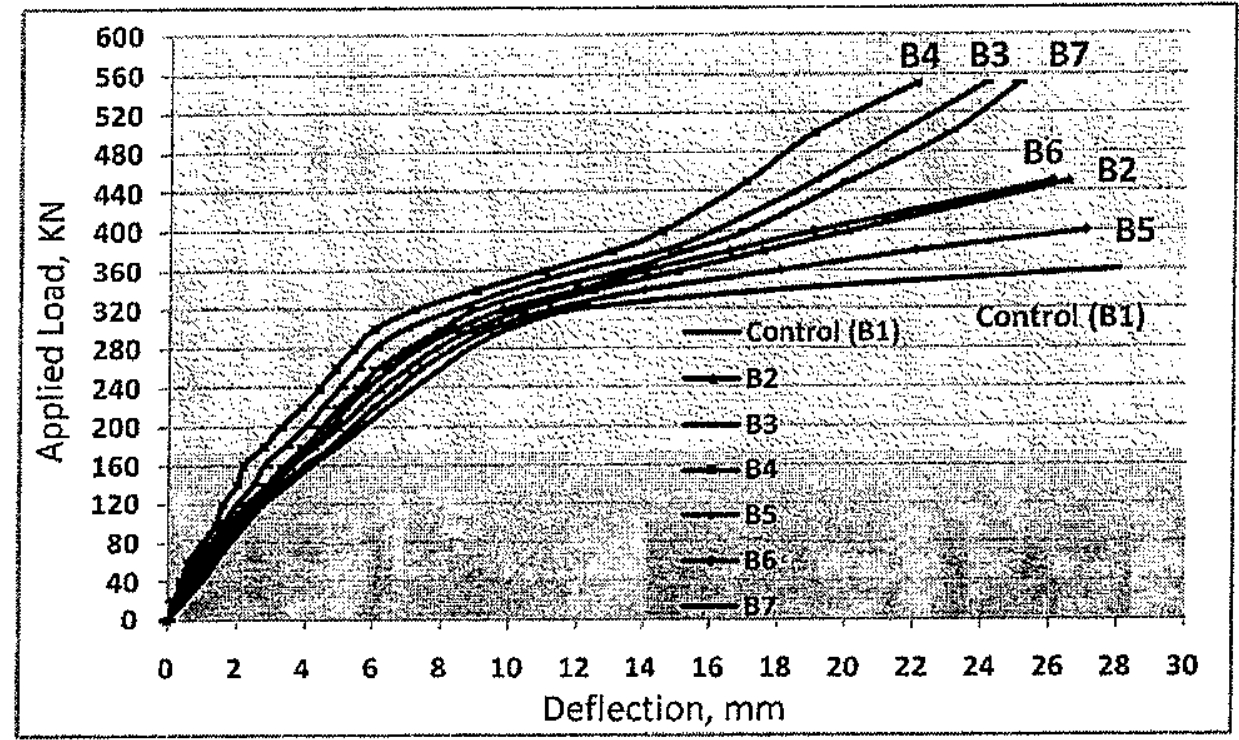

Fig. 5: Load versus mid-span deflection plot for all the strengthened beams

As expected, the stiffness of the tested beams increased with the strengthening by CFRP strips indicated by the decrease in deflection as shown in Fig. 6. The depth of the neutral axis seems to increase with increasing the number of CFRP strips. This is expected since increased tension force, for a given curvature, requires increased compression force. Since the strength of concrete is the same, the increased compressive force capacity is due to the increased compression force provided by a larger depth of the neutral axis.

It was observed that the weakest point of the assemblage (concrete-bond-FRP composite material) is not the concrete-FRP composite interface but the concrete-internal steel interface. Strains in the FRP strips at failure were rather low (between $2.7 \%$ and $4 \%$ ) compared with the ultimate tensile of the material which is $8.5 \%$. 


\subsection{Flexural behavior of beams strengthened by NSM CFRP}

Beams strengthened with one, two, and three near surface mounted CFRP (B5, B6, and B7) increased in ultimate load by $23 \%, 46 \%$, and $69 \%$ respectively, while the mid-span deflections were $27 \mathrm{~mm}, 26 \mathrm{~mm}$, and $25 \mathrm{~mm}$ compared to the deflection value of $28 \mathrm{~mm}$ for the control beam as reported in table 2 above. The relationship between mid-span deflections and the applied load up to failure for beams strengthened with NSM CFRP plates is illustrated in figure 5. Mid span deflections, tensile strains in the main rebars were reduced and an increase of the stiffness of the strengthened beams were noticed with increasing the number of CFRP strips used for the strengthening process.

\subsection{Comparison between the two main strengthening techniques (EB \& NSM CFRP)}

The two strengthening techniques used in this investigation were evaluated and compared to each other in terms of the flexural capacities, mid-span deflections, and load deflection relationship. Fig's. 6 , 7 show the effect of using both the externally bonded and the NSM CFRP laminates on the ultimate load and mid-span deflection respectively.

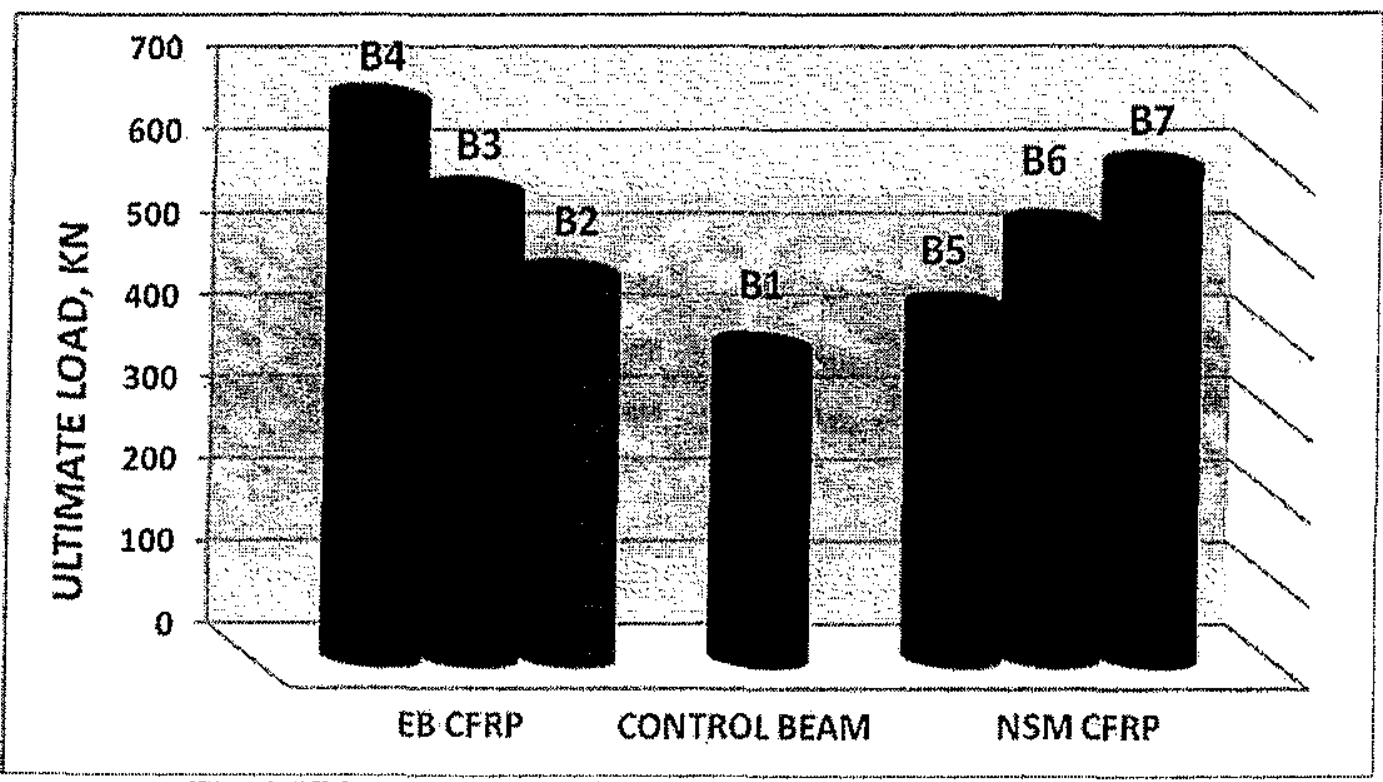

Fig. 6: Ultimate load versus beam type plot for all strengthened beams

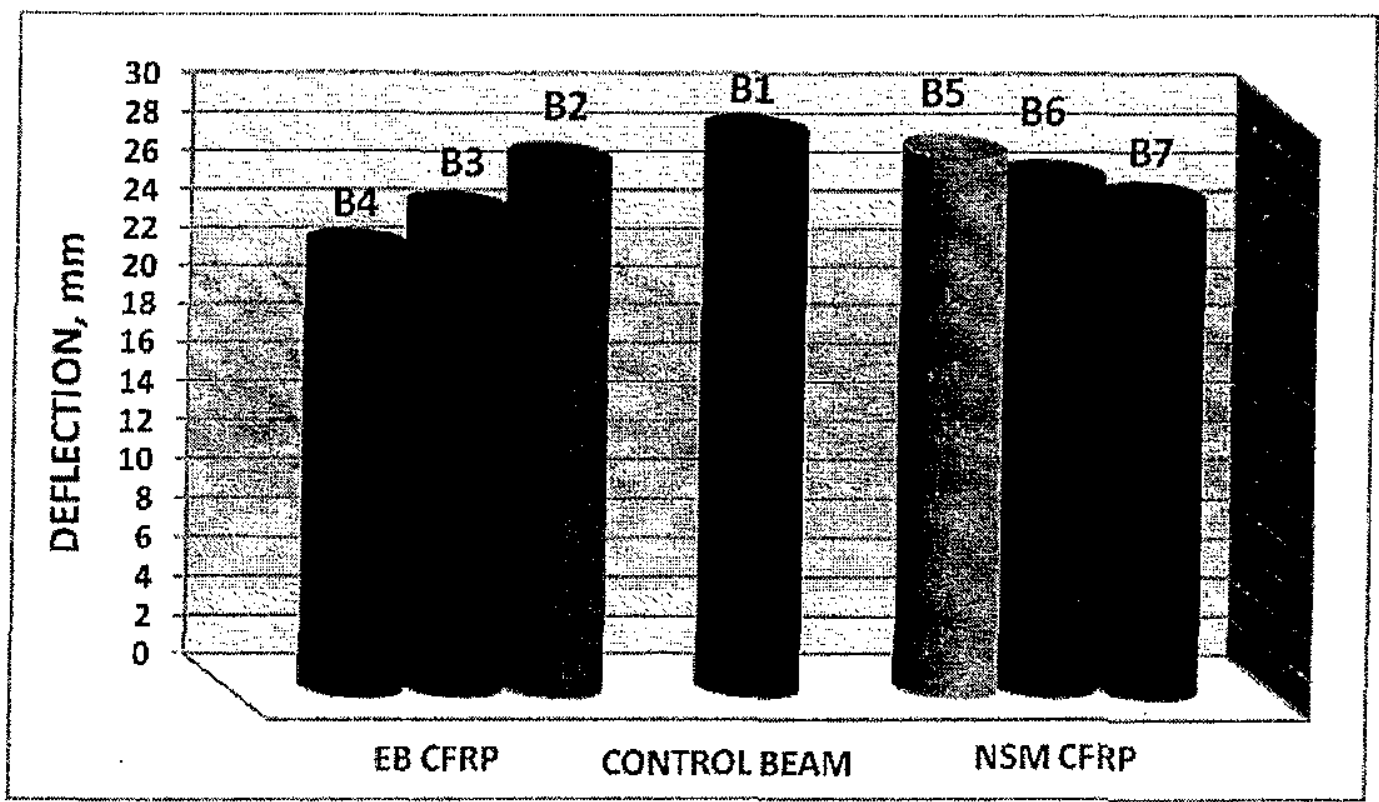

Fig. 7: Deflection versus beam type plot for all strengthened beams 


\subsection{Failure Modes}

In general, previous researches mentioned many types of failure modes for both the externally bonded and the NSM CFRP reinforced beams.

Failure modes of the externally bonded CFRP are; rupture of carbon fibers, crushing of concrete, failure of reinforced bars, peeling-off of the concrete cover near the surface along a weakened layer, cracking in the strengthening layer, cracking in the glue layer, debonding between adhesive and FRP, and debonding at the interface between concrete and adhesive.

The failure modes for the NSM CFRP include; interfacial failure modes, failure at reinforcement adhesive interface, failure at the epoxy concrete interface, cover Splitting, edge Splitting, FRP tensile rupture.

The cracks initiation and its propagation (cracking map) were detected on surfaces of the beams to study the mode of failure for all tested beams. The observed failure modes on the tested beams are different from that of a classical reinforced beams (concrete crushing or failure of the internal steel). Moreover, the failure modes of the externally bonded CFRP reinforced beams are different from those of the near surface mounted CFRP.

\subsection{1 failure modes of the externally bonded CFRP}

All externally reinforced beams using carbon fiber materials have failed in the same manner (the failure of a concrete layer along the internal reinforcement).

The crack patterns of the strengthened beams are different from the control beam, as shown in Figs. 8, 9 , and 10. Strengthened beams had more and closely spaced cracks. As the number of CFRP strips increased, the length of beam over which extensive cracking occurred also increased.

Since the beams were purposely under-reinforced with sufficient shear reinforcement, shear failure did not occur even when the moment capacity was increased by $50 \%$ over the control beam. The influence of the external reinforcement on the development of the cracks is obvious. The beams behaved in an expected fashion under flexural loading. As load increases, flexural cracks increase in number, width and depth. Shear cracks and flexuralshear cracks also appeared, propagating diagonally from the location of loads to the supports. The widest and critical cracks started as flexural cracks opposite the loads, then propagated vertically over the entire depth of the beam due to a combination of flexure and vertical shear as shown in Fig. 10.

The development of the cracks during the reinforcement test is highly influenced by the strengthening with carbon fibers. The start of the first cracking delays, and cracks are more diffusing. Shear cracks occurred at the ends of the strips for values of the load between $70 \%$ and $80 \%$ of the ultimate load. Then those cracks came again near the mid span by using existing flexural cracks. Finally the sudden propagation of a horizontal crack in the concrete steel bond region occurred. This crack run along the weakest surface, which is the concrete-steel interface. As soon as the horizontal crack opened, the concrete separated and the failure occurred.

The decrease of strains and the arresting cracks are considered of the drawbacks of this technique since these were the classical tool for the designer to predict the failure of the structure.

\subsection{2 failure modes of the NSM CFRP}

Beams B5, B6, and B7 strengthened with one, two, and three strips of near surface mounted CFRP failed due to the combination of both the FRP tensile rupture as well as shear failure of a concrete layer between the rebars and the external strengthening layer which was identified by the presence of adhesive on both FRP and concrete after failure, followed by crushing of concrete at compression zone, as shown in Fig. 10.

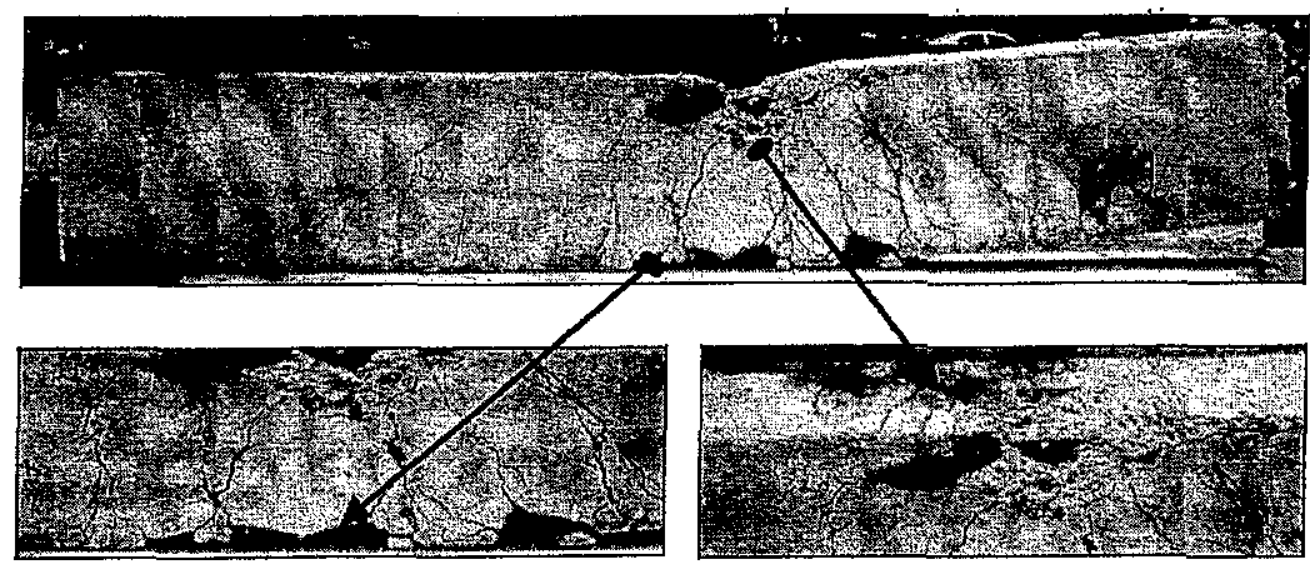

Fig. 8: Failure mode of the control beam (B1) 


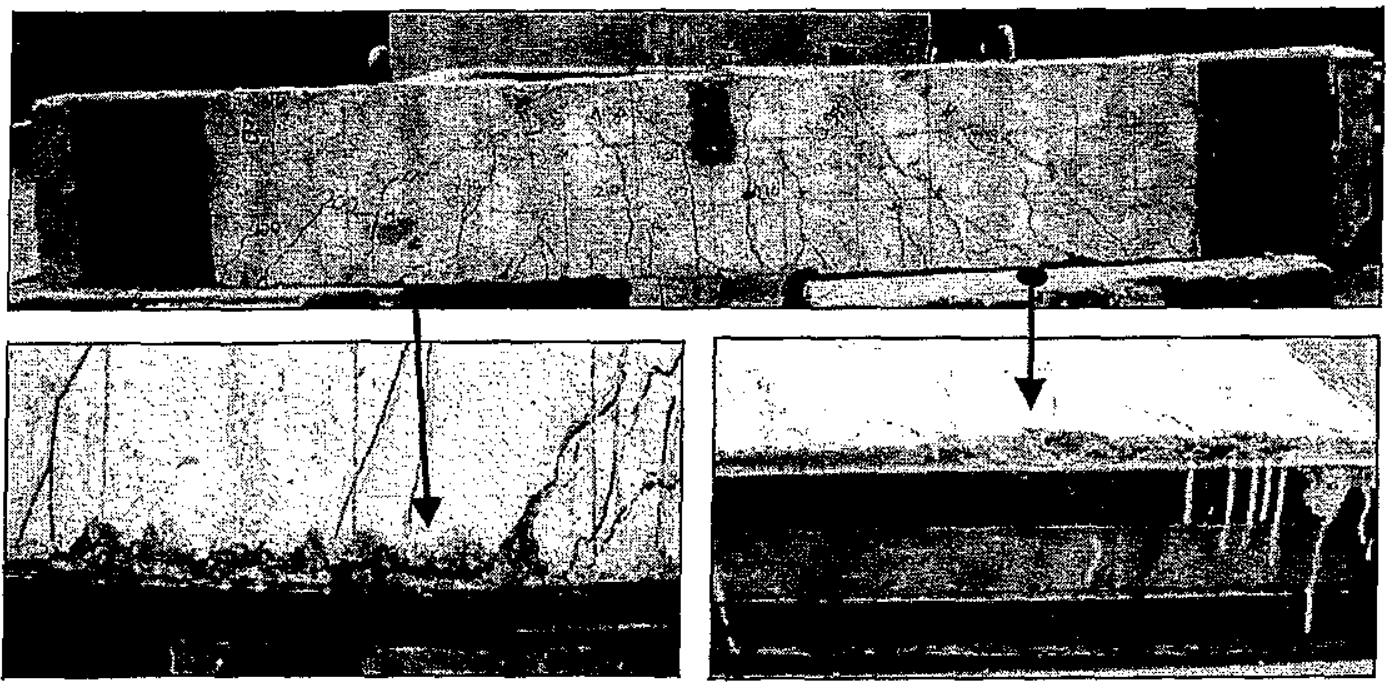

Fig. 9: Failure mode of beam (B3) strengthened with two EB CFRP

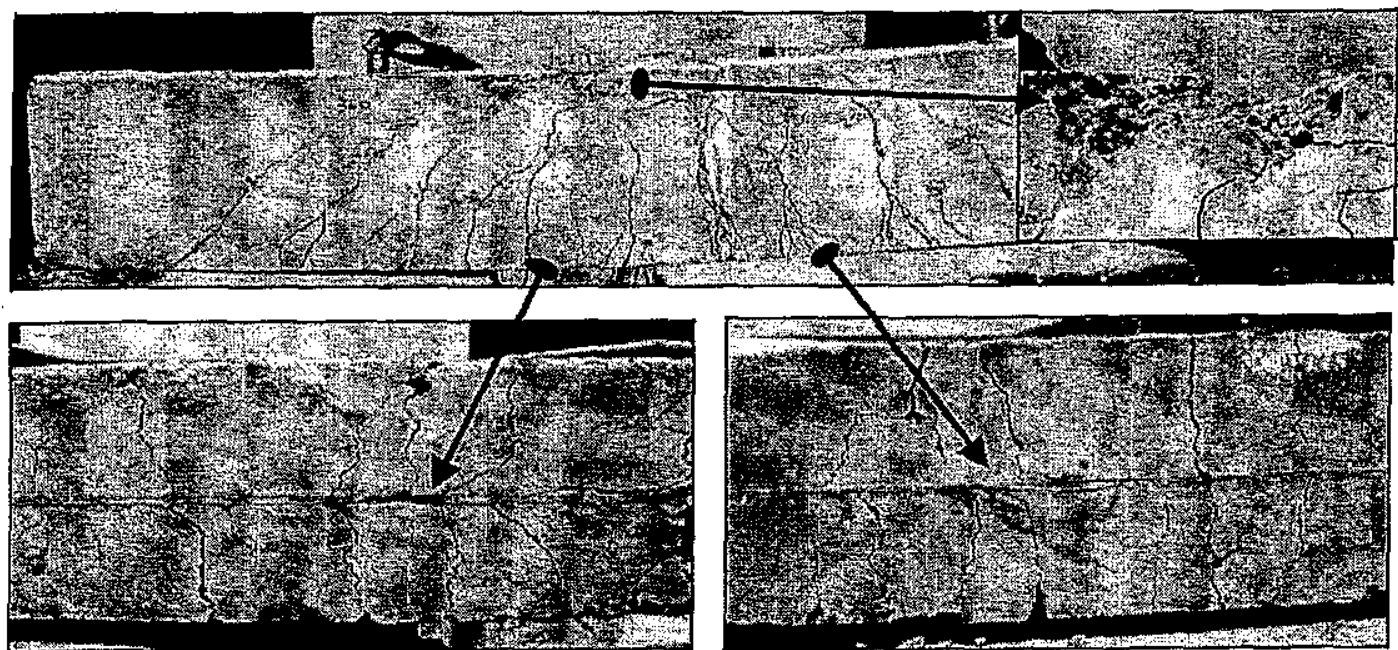

Fig. 10: Failure mode of beam (B5) strengthened with one NSM CFRP

\section{CONCLUSIONS}

Based on the experimental results obtained in the current work, the following conclusions can be drawn:

- Strengthening of reinforced concrete beams using both externally bonded as well as near surface mounted carbon fiber reinforced polymers increase the flexural capacity of R.C beams. The percentage increase in the flexural capacity depends mainly on the number of strips used.

- With regard to structural behavior in flexure of the strengthened R.C. beams, the same amount of NSM reinforcement provides higher flexural capacity and lower deflection up to failure compared to EBR. This could be due to the higher inertia attained by the NSM method and the larger bond surface of the NSM method which induces better anchorage capacity compared with the externally bonded CFRP.
- Externally bonded FRP laminates shows easier installation procedure compared to NSM FRP which requires skilled labors and high technology equipments.

- Beams strengthened with NSM reinforcements show different failure modes than the externally bonded FRP. The mode of failure for the externally bonded FRP was the debonding at the interface between concrete and adhesive. On the other hand, the governing mode of failure for the NSM FRP was the FRP tensile rupture as well as shear failure of a concrete layer between the rebars and the external strengthening layer.

- Clamping or wrapping the ends of the externally bonded FRP laminates is effective in anchoring the laminates.

- FRP strengthening is particularly suitable for strengthening structures with high grade concrete; in such cases the high strength of concrete could be more fully utilized. 


\section{REFERENCES}

[1] Nordin H., and Täljsten B., (2006), "Concrete beams strengthened with prestressed near surface mounted CFRP", $\mathrm{J}$ of Materials in Civil Engineering, ASCE, (10), 81-94.

[2] Zsombor K. S., and György L. B. (2007), "Near surface mounted FRP reinforcement for strengthening of concrete structures", Rperiodica polytechnica Civil Engineering, (51) $1,33-38$.

[3] Meier, U. (1992) "Carbon fiber-reinforced polymers: Modern materials in bridge engineering", Struct. Eng. Int. (IABSE, Zurich, Switzerland) $2,7-12$.

[4] Saadatmanesh, E., and Ehsani, M. R. (1989), "Application of fiber composites in civil engineering", Proceeding of 7th ASCE Structures Congress, New York.

[5] Sharif, A., Al-Sulaimani, G. J., Basunbul, I. A., Baluch, M. H., and Ghaleb, B. N. (1994) "Strengthening of initially loaded reinforced concrete beams using FRP plates", ACI Structural. J., (91) 2, 160-168.

[6] Arduini, M., Di Tommaso, A., and Nanni, A., (1997), "Parametric study of beams with externally bonded FRP reinforcement", $\mathrm{ACI}$ Structural. J., (94) 5, 493-501.

[7] Swamy, R. N., and Mukhopadhyaya, P. (1999), "Debonding of carbon fibre reinforced polymer plate from concrete beams", Eng. Structs and Bldgs., (134) 11, 301-317.

[8] Hassan, $T$ and Rizkalla, S., (2003) "Investigation of Bond in Concrete Structures Strengthened with Near Surface Mounted Carbon Fiber Reinforced Polymer Strips", $J$ of Composites for Construction, ASCE.
[9] Nanni A., (2003) "North American design guidelines for concrete reinforcement and strengthening using FRP: principles, applications and unresolved issues", Construction and Building Materials 17, 439446.

[10] Cruz J., and Barros J., (2002), "Bond behavior of carbon laminates strips into concrete by pullout-bending tests, Proceedings", Int. Symposium on Bond in concrete-from research to standards.

[11]Kotynia R., (2005), "Strain efficiency of nearsurface mounted CFRP-strengthened reinforced concrete beams", Third international conference composites in construction, Lyon.

[12] Teng J. G., de Lorenzis, L., Wang B., Li. R., Wong, T. N., and Lam, L., (2006), "Debonding failures of $\mathrm{RC}$ beams strengthened with near surface mounted CFRP Strips", J of Composites for Construction, ASCE (10) 2, 92-105.

[13] Carolin, A., Nordin, M. and Taljsten, B., (2001), "Concrete beams strengthened with near surface mounted reinforcement of CFRP", Proceeding of Int. Conf. on FRP Composites in Civil Engineering, Hong Kong.

[14] Nordin, H., Taljsten, B., and Carolin, A., (2001), "Concrete beams strengthened with prestressed near surface mounted reinforcement", Proceeding of Int. Conf. on FRP Composites in Civil Engineering, Hong Kong.

[15] Maria A. A., Marianovella L., and Marisa P., (2007), "Bond Performances of FRP RebarsReinforced Concrete", $J$ of Materials in Civil Engineering, ASCE, March, 260-273. 